\title{
Electron Beam Powder Bed Fusion of $\gamma$-Titanium Aluminide: Effect of Processing Parameters on Part Density, Surface Characteristics, and Aluminum Content
}

\author{
Juliane Moritz ${ }^{1,2, *}$, Mirko Teschke ${ }^{3} \mathbb{D}$, Axel Marquardt 1,2 ${ }^{\mathbb{D}}$, Lukas Stepien ${ }^{2}$, Elena López ${ }^{2}$, Frank Brückner ${ }^{2,4}$, \\ Marina Macias Barrientos ${ }^{3}$, Frank Walther ${ }^{3}$ DD and Christoph Leyens ${ }^{1,2}$
}

1 Institute of Materials Science (IfWW), Technische Universität Dresden, 01069 Dresden, Germany; axel.marquardt@tu-dresden.de (A.M.); christoph.leyens@tu-dresden.de (C.L.)

2 Department of Additive Manufacturing and Printing, Fraunhofer Institute for Material and Beam Technology IWS, 01277 Dresden, Germany; lukas.stepien@iws.fraunhofer.de (L.S.); elena.lopez@iws.fraunhofer.de (E.L.); frank.brueckner@iws.fraunhofer.de (F.B.)

3 Department of Materials Test Engineering (WPT), TU Dortmund University, 44227 Dortmund, Germany; mirko.teschke@tu-dortmund.de (M.T.); marina.macias@tu-dortmund.de (M.M.B.); frank.walther@tu-dortmund.de (F.W.)

4 Department of Engineering Sciences and Mathematics, Luleå University of Technology, 97187 Luleå, Sweden

* Correspondence: juliane.moritz@iws.fraunhofer.de

check for updates

Citation: Moritz, J.; Teschke, M.; Marquardt, A.; Stepien, L.; López, E.; Brückner, F.; Macias Barrientos, M.; Walther, F.; Leyens, C. Electron Beam Powder Bed Fusion of $\gamma$-Titanium Aluminide: Effect of Processing Parameters on Part Density, Surface Characteristics, and Aluminum Content. Metals 2021, 11, 1093. https://doi.org/10.3390/met11071093

Academic Editors: Wojciech Szkliniarz, Agnieszka Szkliniarz and Tomasz Czujko

Received: 31 May 2021

Accepted: 7 July 2021

Published: 9 July 2021

Publisher's Note: MDPI stays neutral with regard to jurisdictional claims in published maps and institutional affiliations.

Copyright: (c) 2021 by the authors. Licensee MDPI, Basel, Switzerland. This article is an open access article distributed under the terms and conditions of the Creative Commons Attribution (CC BY) license (https:// creativecommons.org/licenses/by/ $4.0 /)$.

\begin{abstract}
Gamma titanium aluminides are very interesting for their use in high-performance applications such as aircraft engines due to their low density, high stiffness and favorable high-temperature properties. However, the pronounced brittleness of these intermetallic alloys is a major challenge for their processing through conventional fabrication methods. Additive manufacturing by means of electron beam powder bed fusion (EB-PBF) significantly improves the processability of titanium aluminides due to the high preheating temperatures and facilitates complex components. The objective of this study was to determine a suitable processing window for EB-PBF of the TNM-B1 alloy (Ti-43.5Al-4Nb-1Mo-0.1B), using an increased aluminum content in the powder raw material to compensate for evaporation losses during the process. Design of experiments was used to evaluate the effect of beam current, scan speed, focus offset, line offset and layer thickness on porosity. Top surface roughness was assessed through laser scanning confocal microscopy. Scanning electron microscopy, electron backscatter diffraction (EBSD) and energy-dispersive X-ray spectroscopy (EDX) were used for microstructural investigation and to analyze aluminum loss depending on the volumetric energy density used in EB-PBF. An optimized process parameter set for achieving part densities of $99.9 \%$ and smooth top surfaces was derived. The results regarding microstructures and aluminum evaporation suggest a solidification via the $\beta$-phase.
\end{abstract}

Keywords: titanium aluminide; additive manufacturing; electron beam powder bed fusion; electron beam melting; process parameters; surface roughness; microstructure; aluminum evaporation

\section{Introduction}

Gamma titanium aluminides have been the subject of extensive research activities for more than 30 years due to their high specific strength and stiffness, good oxidation resistance, and favorable creep properties, which make them suitable for high-temperature applications in aviation and automotive industries [1,2]. With a density of around $4 \mathrm{~g} / \mathrm{cm}^{3}$, titanium aluminides are a lightweight substitute for the much heavier nickel-base superalloys which are currently widely used in jet engines, thus reducing greenhouse gas emissions and fossil fuel consumption [1,3].

Alloy design has led to the development of the TNM-B1 alloy with a nominal composition of Ti-43.5Al-4Nb-1Mo-0.1B (in at.\%), which is a prominent representative of the 3rd generation titanium aluminides and the so-called TNM alloy family. The alloy has been 
comprehensively described in a review paper by Clemens and Mayer [1]. Niobium and molybdenum both act as $\beta$-stabilizing elements and alter the high-temperature properties such as oxidation resistance and creep behavior [1,4]. Thus, the maximum application temperature of titanium aluminide alloys could be extended to $750{ }^{\circ} \mathrm{C}[3,5]$. The addition of boron primarily has a grain refining effect [1,4].

At room temperature, the main occurring phases are the face-centered tetragonal $\gamma$-TiAl phase, the hexagonal $\alpha_{2}-\mathrm{Ti}_{3} \mathrm{Al}$ phase, and the body-centered cubic $\beta_{0}$-TiAl phase $[1,6]$. The presence of the $\beta_{0}$-phase further reduces the room temperature ductility of the already brittle material. However, at elevated temperatures, it is transformed into the disordered body-centered cubic $\beta$-phase with an increased number of independent slip systems, thus resulting in the favorable hot workability of TNM-B1 [7].

Nevertheless, conventional processing of titanium aluminides remains challenging [8]. The evolution of additive manufacturing technologies has opened up new processing routes for manufacturing near net shaped complex components with high relative densities [9]. Among those technologies, electron beam powder bed fusion (EB-PBF), also widely known as electron beam melting (EBM), is particularly suited for titanium aluminide alloys [10]. EB-PBF is a powder bed-based additive manufacturing process which relies on an electron beam as energy source. Electrons are emitted from a cathode, and the beam is then focused and deflected by a set of electromagnetic lenses within the column unit of the EB-PBF machine [11]. With this setup, beam deflection velocities of up to $10^{5} \mathrm{~m} / \mathrm{s}$ are achievable. Typical process pressures are in the range of $10^{-4}$ to $10^{-5} \mathrm{mbar}$ [8]. Each process cycle starts with the application of a powder layer with a defined layer thickness in the build chamber. The subsequent heat input is divided into two steps: First, a defocused beam is scanned over the build area to slightly sinter the particles in the powder bed. This is to avoid so-called "smoke" as a consequence of repulsive forces between particles due to electrostatic charging. Then, the electron beam is focused to melt the respective component contours and cross-section areas before the build platform is lowered and a new layer of powder is applied [12].

Since EB-PBF is conducted under vacuum conditions, oxygen and nitrogen pickup of the material can be limited, which is crucial for processing titanium aluminide alloys $[10,13]$. Moreover, for manufacturing titanium aluminide components, the process is operated at high process temperatures of around $1000{ }^{\circ} \mathrm{C}$, which has been shown to successfully avoid cracking of the parts, as is often observed for other additive manufacturing processes such as laser powder bed fusion $[8,10]$.

First attempts to process titanium aluminides by means of EB-PBF starting from pre-alloyed and blended powders were conducted by Cormier et al. [14]. Since then, several research groups have advanced both the alloy design and the process capabilities. Among the alloys studied, Ti-47Al-2Cr-2Nb [15-18] and Ti-48Al-2Cr-2Nb [9,19-21] have been most intensively investigated in terms of process parameters, microstructure, heat treatments, and mechanical properties. The Ti- $48 \mathrm{Al}-2 \mathrm{Cr}-2 \mathrm{Nb}$ alloy is well known for its application in the low-pressure turbine of the $\mathrm{GEnx}^{\mathrm{TM}}$ engine [2]. A first systematic study regarding the fabrication of this alloy by means of EB-PBF was published by Biamino et al. [19], who achieved parts with a high relative density and a fine and homogeneous microstructure. Schwerdtfeger et al. [20] thoroughly investigated the influence of EB-PBF process parameters such as beam parameters, layer thickness, and preheating temperature on the microstructure and local composition of Ti- $48 \mathrm{Al}-2 \mathrm{Cr}-2 \mathrm{Nb}$ and found that the results were strongly linked to the total energy input. The sensitivity of the microstructure to the processing conditions was confirmed by Tang et al. [22] for Ti-45Al-7Nb-0.3W. While an insufficient energy input resulted in misconnections and defects, an excessive heat input enforced inhomogeneous microstructures and variations in chemical composition. Wartbichler et al. [13] studied the microstructural features of TNM-B1 manufactured via EB-PBF and found an inhomogeneous distribution of the aluminum content and the present phases as well as a pronounced solidification texture along the build direction. 
A study performed by Bieske et al. [23] suggests that the local evaporation of aluminum, which leads to inhomogeneities in the microstructure, does not only occur during melting, but already during the heating step of the EB-PBF process. The authors therefore propose a capsule technology, where a near net shaped capsule containing sintered powder is manufactured by EB-PBF and then consolidated in a subsequent hot isostatic pressing (HIP) step, as an alternative processing route for fabricating nearly dense TNM-B1 components. Another strategy to achieve homogeneous microstructures and isotropic properties after EB-PBF is to design process-adapted titanium aluminide alloys which exhibit peritectic solidification behavior and are less likely to form textures than the $\beta$-solidifying TNM-B1 alloy [3,7].

In order to fully exploit the possibilities provided by EB-PBF, a profound understanding of the influence of the individual process parameters and their interactions on microstructure and part quality is crucial. Therefore, starting from raw material powder with an increased aluminum content to compensate for $\mathrm{Al}$ loss during processing, this study investigated a large parameter field for the EB-PBF of TNM-B1 in terms of the resulting part densities, surface qualities, and aluminum evaporation to derive a suitable process window for the processing of this titanium aluminide alloy.

\section{Materials and Methods}

Spherical gas atomized pre-alloyed powder with the nominal chemical composition Ti-46.5Al-4Nb-1Mo-0.1B and a particle size distribution between $60 \mu \mathrm{m}$ and $145 \mu \mathrm{m}\left(\mathrm{D}_{50}\right.$ of $83.6 \mu \mathrm{m}$ ) was obtained from GfE Metalle und Materialien $\mathrm{GmbH}$. The aluminum content had been increased by approximately 3 at. \% in comparison to conventional cast TNM-B1 ingots to compensate for the expected aluminum evaporation during the EB-PBF process. Chemical composition and particle size distribution were verified via ICP-OES analysis, which was performed at HDZ Prüf- und Analyselabor Aachen (Aachen, Germany), and by means of laser diffraction using a Malvern Mastersizer 2000 (Malvern Panalytical, Malvern, United Kingdom), respectively.

All EB-PBF experiments were performed on an Arcam A2X machine using the software EBM Control 3.2 (Arcam EBM, Gothenburg, Sweden). Statistically designed experiments were used in order to find a suitable processing window for TNM-B1 and to examine the influence of the individual process parameters on part density. In this study, a central composite design was chosen, which provides a quadratic description model and can thus also represent non-linear relationships between the variables [24]. Experimental design and evaluation of results were performed using the software Minitab ${ }^{\circledR} 19$ (Minitab GmbH, Munich, Germany). The beam current $I_{\text {beam }}$, the scanning speed $v_{\text {scan }}$, the focus offset $f_{\text {offset }}$, and the line offset $l_{\text {offset }}$ were varied as continuous factors, while the layer thickness $t$ was investigated as a categorical factor at $50 \mu \mathrm{m}$ and $70 \mu \mathrm{m}$, respectively. During heating and melting, the material is transformed from a loose powder packing to a nearly dense solid, which is associated with volume shrinkage due to the reduction in porosity [25]. As a consequence, the actual layer thickness is greater than the theoretical layer thickness, which is why a particle size distribution ranging from $60 \mu \mathrm{m}$ to $145 \mu \mathrm{m}$ can be used with the aforementioned layer thicknesses [26]. The values for each factor are specified in Table 1.

A total number of 62 runs was required to cover all points of the statistical experimental design. Cuboids with an edge length of $10 \mathrm{~mm} \times 10 \mathrm{~mm} \times 14 \mathrm{~mm}$ were chosen for analyzing part density and microstructure. For investigating the top surface roughness, larger cuboids with a square base of $23 \mathrm{~mm} \times 23 \mathrm{~mm}$ and a height of $14 \mathrm{~mm}$ were used. However, the characterization of the surface topography was only performed on a part of the experimental plan representing the cube points and the central point in order to limit the measuring effort. Moreover, the influence of the focus offset on surface roughness was not investigated. Thus, the number of samples for surface roughness measurement was reduced to nine specimens for each layer thickness. 
Table 1. Values for continuous and categorical factors used in central composite design.

\begin{tabular}{cccccc}
\hline $\begin{array}{c}\text { Continuous } \\
\text { Factors }\end{array}$ & $\begin{array}{c}\text { Axial Point } \\
\text {-Low Level }\end{array}$ & $\begin{array}{c}\text { Cube Point } \\
\text {-Low Level }\end{array}$ & $\begin{array}{c}\text { Central } \\
\text { Point }\end{array}$ & $\begin{array}{c}\text { Cube Point } \\
\text {-High Level }\end{array}$ & $\begin{array}{c}\text { Axial Point } \\
\text {-High Level }\end{array}$ \\
\hline $\begin{array}{c}\text { Beam } \\
\text { current/mA }\end{array}$ & 7.5 & 10 & 12.5 & 15 & 17.5 \\
\hline $\begin{array}{c}\text { Scan } \\
\text { speed } / \mathrm{mm} / \mathrm{s}\end{array}$ & 1750 & 2500 & 3250 & 4000 & 4750 \\
\hline Focus offset/mA & 1 & 2 & 3 & 4 & 5 \\
\hline Line offset/mm & 0.1 & 0.15 & 0.2 & 0.25 & 0.3 \\
\hline $\begin{array}{c}\text { Categorical } \\
\text { factor }\end{array}$ & Low value & & High value & \\
\hline $\begin{array}{c}\text { Layer } \\
\text { thickness } / \mu \mathrm{m}\end{array}$ & 50 & & 70 & \\
\hline
\end{tabular}

For all build jobs, a $150 \mathrm{~mm} \times 150 \mathrm{~mm}$ stainless steel start plate was used, which was preheated to $1020^{\circ} \mathrm{C}$ in the beginning of each process. The process was operated under a controlled vacuum atmosphere in the range of $10^{-3}$ mbar.

After completion of the build job, the top surfaces of all samples were captured using a Canon EOS 5D camera (Canon, Tokio, Japan) for visual inspection of the surface quality. Subsequently, the cuboids for porosity analysis were cut along the xz-plane and then ground and polished for metallographic analysis. Light microscopic images were taken of all cross-sections using an Olympus GX51 inverted optical microscope (Olympus K.K., Tokio, Japan). Porosity and pore size were determined by means of gray scale analysis on those images using the software ImageJ (National Institutes of Health, Bethesda, USA). In the following, the relative density is used instead of the porosity to describe the specimens. Within this study, the term relative density refers to the percentage of dense material calculated from image analysis.

Scanning electron microscopy (SEM) microstructural analysis was performed with a JEOL JSM-6610LV scanning electron microscope (JEOL Ltd, Tokio, Japan) using the backscatter electron detector. The evaluation of the aluminum content was performed by means of energy-dispersive X-ray spectroscopy (EDX). For this purpose, a Zeiss DSM 950 SEM (Carl Zeiss AG, Oberkochen, Germany) equipped with an EDX detector was utilized. Detailed microstructural investigations of selected specimens were carried out with the focused ion beam scanning electron microscope Crossbeam XB 550L (FIB-SEM, Carl Zeiss AG, Oberkochen, Germany) with an integrated electron backscatter diffraction (EBSD) detector (NordlysMax ${ }^{3}$, Oxford Instruments, Abingdon, United Kingdom). The EBSD mapping was performed at $20 \mathrm{kV}$ acceleration voltage with $5000 \times$ magnification using crystallographic data of OINA phases data base.

Top surface roughness was measured on the $23 \mathrm{~mm} \times 23 \mathrm{~mm}$ surfaces of the larger cuboids using a Keyence VK-X250 laser scanning confocal microscope (Keyence Corporation, Osaka, Japan). The surface topography was acquired on three randomly selected areas of $1500 \mu \mathrm{m} \times 1500 \mu \mathrm{m}$ in the center of each sample surface. In order to minimize noise of the measurement, the cut-off value for the high-pass areal Gaussian S-filter was set to $2.0 \mu \mathrm{m}$. For the low-pass L-filter, a nesting index value of $0.8 \mathrm{~mm}$ was selected.

\section{Results}

\subsection{Evaluation of Central Composite Design}

As described above, a central composite design was used for investigating the interrelation between the EB-PBF processing parameters and the porosity occurring in the samples. The acquired data from the image analysis of the metallographic cross-sections were used for analyzing the central composite design. The relative density was chosen as the response variable to identify the significance of each process parameter and to deduct a model for quantifying their influence. For building the model, a two-sided 95\% confidence interval 
was used. A stepwise regression was applied, which means that the model is incrementally refined by adding or removing terms according to their $p$-value. For this purpose, an alpha-to-enter and an alpha-to-remove value are defined, on the basis of which it is decided whether a variable is significant or not. In this study, the values for alpha-to-enter and alpha-to-remove were set to 0.15 , respectively. Among the total of 62 samples examined, five values for the relative density were identified as influential observations with a strong leverage effect on the regression. In all five cases, the measured relative densities were below $90 \%$. These values were, therefore, excluded from the regression model in order to obtain a better curve fitting for the higher relative densities, which are more relevant for technical applications. For predicting the achievable relative densities for a layer thickness of $50 \mu \mathrm{m}$ and $70 \mu \mathrm{m}$, the model Equations (1) and (2) (presented in uncoded units) were derived with an $\mathrm{R}^{2}$ of $82.1 \%$, respectively.

Layer thickness of $50 \mu \mathrm{m}$ (Equation (1)):

Relative density (\%)

$$
\begin{aligned}
& =92.21+0.952 * I_{\text {beam }}+0.000458 * v_{\text {scan }}+9.0 * l_{\text {offset }}-0.0528 * I_{\text {beam }} * I_{\text {beam }}-88.7 \\
& * l_{\text {offset }} * l_{\text {offset }}+2.807 * I_{\text {beam }} * l_{\text {offset }}-0.00422 * v_{\text {scan }} * l_{\text {offset }}
\end{aligned}
$$

Layer thickness of $70 \mu \mathrm{m}$ (Equation (2)):

Relative density (\%)

$$
\begin{aligned}
& =92.53+1.141 * I_{\text {beam }}+0.000458 * v_{\text {scan }}-9.1 * l_{\text {offset }}-0.0528 * I_{\text {beam }} * I_{\text {beam }}-88.7 \\
& * l_{\text {offset }} * l_{\text {offset }}+2.807 * I_{\text {beam }} * l_{\text {offset }}-0.00422 * v_{\text {scan }} * l_{\text {offset }}
\end{aligned}
$$

As described above, only terms identified as significant based on their $p$-value were included in the equation. Based on the model equations, factorial plots were created for visualization of the relationship between the relative density and the individual process parameters. Figure 1 displays the main effect plots for beam current, scan speed and line offset, respectively. The focus offset was found to have no significant influence on the relative density within the investigated range and is, therefore, not considered further in the following.

In each graph, the mean predicted relative density and the corresponding 95\% prediction interval are shown for the two different layer thicknesses. It can be observed that the predicted relative densities for the higher layer thicknesses of $70 \mu \mathrm{m}$ are generally lower than those for $50 \mu \mathrm{m}$. The influence of the layer thickness becomes more noticeable with decreasing beam current as well as with increasing line offset. For beam current and line offset, the regression model contains first- and second-order terms, which explains the curvature of the graphs. For the beam current at a layer thickness of $70 \mu \mathrm{m}$, a higher relative density is predicted when the beam current is increased, while for a layer thickness of $50 \mu \mathrm{m}$, the curve reaches a maximum at approximately $14.5 \mathrm{~mA}$ and then slightly decreases for higher beam currents. Regarding line offset, it can be seen that the relative density rapidly decreases with higher offset values when a layer thickness of $70 \mu \mathrm{m}$ is used. With a layer thickness of $50 \mu \mathrm{m}$, the predicted density shows a maximum at $0.175 \mathrm{~mm}$ line offset. It is evident from Figure 1 that the predicted relative densities increase linearly when lower scan speeds are chosen.

It should, however, be noted that due to the exclusion of outliers with large residuals, the relative density may be overestimated by the model, particularly for low energy inputs. As a result, the values for the predicted relative density may even exceed $100 \%$. Moreover, it is conceivable that the regression model containing only first and second order terms is not sufficient to ideally describe the interrelation between the response variable and the process parameters. Consequently, while the model can provide valuable information about the qualitative relationships between the individual variables, it should not be overinterpreted in terms of its capacity to quantitatively predict relative densities. 
(a)

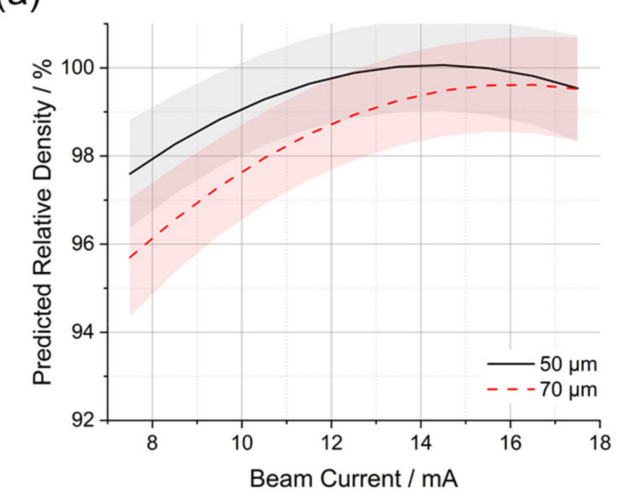

(c)

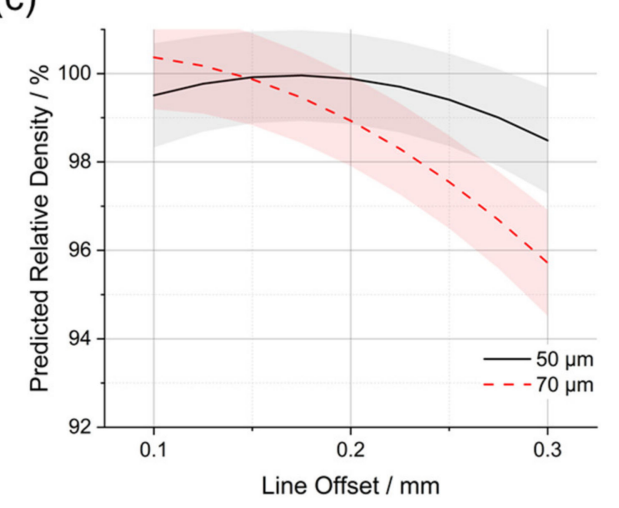

(b)

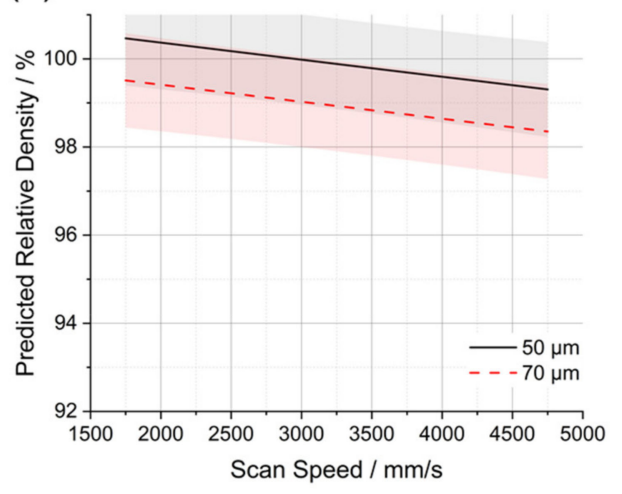

Figure 1. Main effects plots for influence of (a) beam current, (b) scan speed, and (c) line offset on predicted relative density. The shaded areas mark the $95 \%$ prediction intervals.

In order to illustrate the interdependencies of the EB-PBF process parameters, interaction plots were used (see Figure 2). In all cases, the layer thickness was kept at a constant level of $70 \mu \mathrm{m}$.

Figure $2 \mathrm{a}, \mathrm{b}$ clearly show the increase in predicted relative densities with increasing beam current. The curve in Figure 2a suggests that although higher densities can be achieved when the scan speed is reduced at a given value for the beam current, the effect is rather small. In comparison to that, the difference between the single curves as shown in Figure $2 b$ for three different line offsets is more pronounced. Line offset also seems to affect the slope of the curve in Figure 2c, which presents the dependency of the predicted relative density on the scan speed. When a line offset of $0.25 \mathrm{~mm}$ is used, the relative density is expected to decrease with increasing scan speed, whereas with a line offset of $0.15 \mathrm{~mm}$, the scan speed seems to have little influence on part density.

Overall, the obtained regression model suggests that an increase in beam current and a decrease in line offset are the most influential adjustments to maximize the relative part density. Furthermore, a slower scan speed and a lower layer thickness may be expected to have a beneficial effect.

\subsection{Selection of Optimized Parameter Set}

Apart from the relative density, samples were also evaluated by visual inspection of their top surfaces. In Figure 3, the surfaces of five representative specimens as well as the corresponding metallographic cross-sections are shown. 
(a)

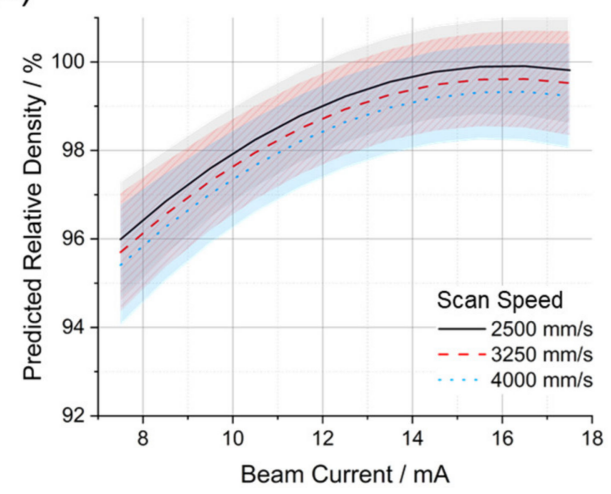

(c)

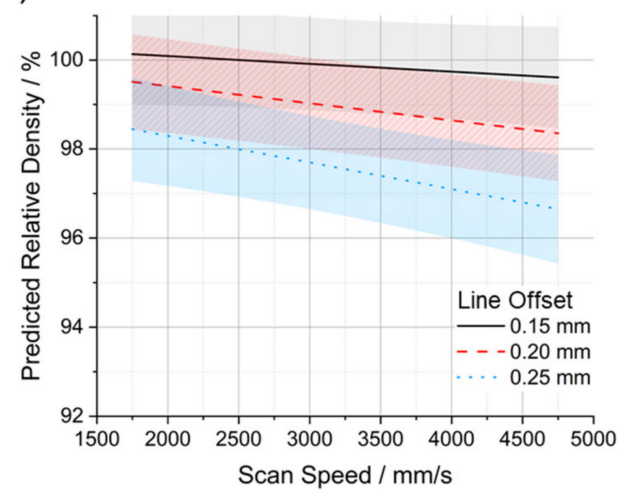

(b)

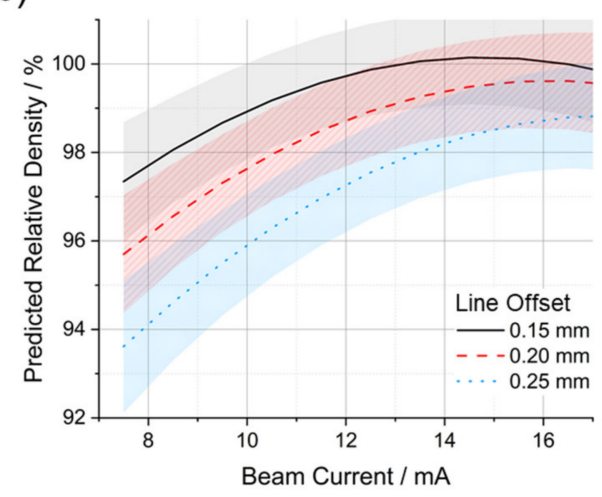

Figure 2. Interaction plots for the effect of (a) beam current at varied scan speeds, (b) beam current at varied line offsets and (c) scan speed at varied line offsets with respect to predicted relative densities. The shaded areas mark the $95 \%$ prediction intervals.

(a)
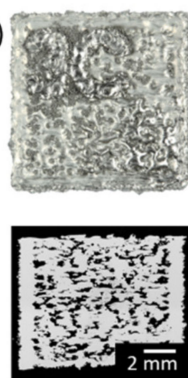

(b)
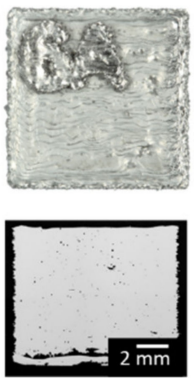

(c)
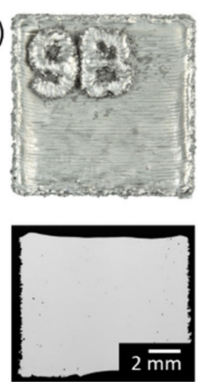

(d)
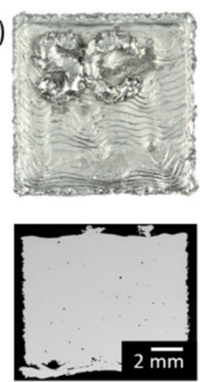

(e)
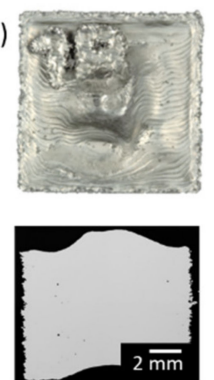

Figure 3. Top surface morphologies and cross-sectional images for representative samples with top surfaces categorized as (a) porous, (b) slightly porous, (c) even, (d) wavy, and (e) swelling. duced:

The five following categories for visual categorization of the top surfaces were intro-

1. Porous: the surfaces exhibit a large amount of surface pores with almost no consistent melt tracks and a very irregular appearance;

2. Slightly porous: the individual melt tracks can be distinguished, but areas with surface pores and unmelted powder particles are visible;

3. Even: smooth surfaces with parallel, undistorted melt tracks;

4. Wavy: the surfaces are mostly flat, but the melt tracks show noticeable curls and distortions;

5. Swelling: the sample surfaces show conspicuous bulges and irregularities 
As can be seen from Figure 3a, porous surfaces were found to be an indicator for an overall high porosity within the specimen volume. The pores were irregularly shaped and often formed large cavities spanning across several layers. The cross-section of the slightly porous sample in Figure $3 \mathrm{~b}$ reveals elongated, sharp-edged defects as a result of misconnections between two consecutive layers as well as spherical, randomly distributed pores, which are often classified as gas pores. It is commonly assumed that this gas porosity originates from gas inclusions in the powder particles, interstices between individual particles in the powder bed, or turbulences within the melt pool. Due to the rapid solidification during the process, the gas might be entrapped in the solidified material before it can escape from the melt pool [3]. The specimens displayed in Figure 3c-e) all have relative densities above $99.85 \%$. However, the bulges in Figure 3 e tend to grow with each additional layer and might finally lead to the abortion of the entire build process [8]. Similarly, the material displacement and surface inhomogeneities observed on the samples with wavy surfaces should be avoided. Therefore, it was concluded that relative density should not be the only selection criterion for an appropriate parameter set for EB-PBF of TNM-B1. Instead, the assessment of the top surface quality should also be included in the parameter selection process. This is in line with an approach presented by Jüchter et al. [27], who also applied a relative density of at least $99.5 \%$ and a smooth top surface as criteria for defining a suitable EB-PBF processing window for Ti-6Al-4V.

Consequently, a parameter set with a suitable energy input had to be determined in order to obtain components with a high relative density on the one hand and to avoid swelling on the other hand. For this purpose, all samples were mapped according to the classification of their top surfaces in the diagram shown in Figure 4, in which the line offset is plotted against the line energy for the two investigated layer thicknesses, respectively. The line energy $E_{L}$ is defined according to the following equation (Equation (3)):

$$
E_{L}=\frac{U * I_{\text {beam }}}{v_{\text {scan }}}
$$

where $U$ is the acceleration voltage of $60 \mathrm{kV}$, while $I_{\text {beam }}$ and $v_{\text {scan }}$ represent beam current and scan speed [7]. Additionally, iso-lines of identical areal energy input $E_{A}$ are included in the diagrams. The areal energy input $E_{A}$ can be described by Equation (4):

$$
E_{A}=\frac{E_{L}}{l_{\text {offset }}}
$$

as the quotient of line energy and line offset. The influence of the layer thickness $t$ on total energy input is taken into account in the equation for the volumetric energy density $E_{V}$ (Equation (5)) [28]:

$$
E_{V}=\frac{E_{A}}{t}
$$

(a)

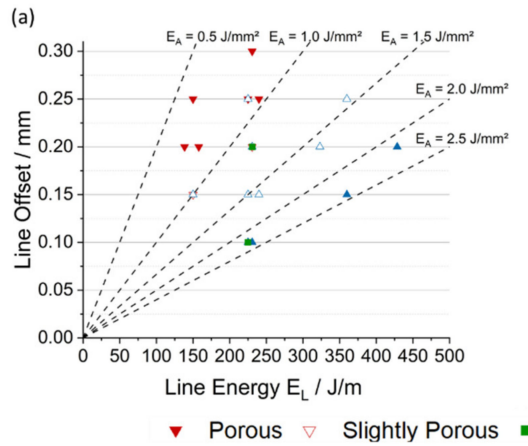

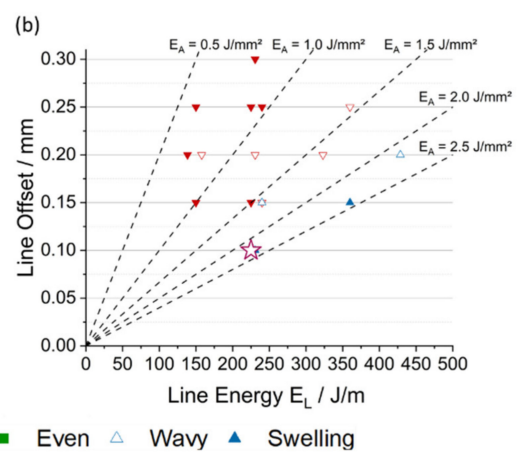

Figure 4. Top surface qualities depending on line energy and line offset for a layer thickness of (a) $50 \mu \mathrm{m}$ and (b) $70 \mu \mathrm{m}$. The dashed lines indicate parameter combinations with identical areal energy input. The optimized parameter set is marked with a star symbol. 
Figure 4 indicates a correlation between top surfaces quality and energy input during the EB-PBF process. For both layer thicknesses, an areal energy input of less than $1.0 \mathrm{~J} / \mathrm{mm}^{2}$ resulted in porous or slightly porous surfaces and high porosity in the bulk material for the majority of specimens. However, comparing Figure 4a,b for higher areal energy inputs, differences between the two layer thicknesses become evident. With a layer thickness of $50 \mu \mathrm{m}$, samples fabricated with an $\mathrm{E}_{\mathrm{A}}$ of $1.5 \mathrm{~J} / \mathrm{mm}^{2}$ or higher show a tendency towards wavy surfaces, whereas samples manufactured with the same areal energy input but a higher layer thickness of $70 \mu \mathrm{m}$ still exhibit some pores on the top surface. The optimum energy input for the higher layer thickness appears to range between 2.0 and $2.5 \mathrm{~J} / \mathrm{mm}^{2}$.

Based on the results of statistical experimental design and the observations from top surface characterization, an optimized set of parameters for processing TNM-B1 via EB-PBF was derived. In all following diagrams in this study, the values obtained using the optimized parameter set are highlighted by a star symbol, in order to facilitate a comparison within the parameter field investigated in this study. A layer thickness of $70 \mu \mathrm{m}$ was chosen in order to achieve higher build-up rates in the process. A volumetric energy density of $32.1 \mathrm{~J} / \mathrm{mm}^{3}$ was found to be suitable for producing nearly dense parts with even top surfaces. The settings for each individual process parameter of the optimized parameter set as well as the achieved relative density are summarized in Table 2.

Table 2. Process parameters and achieved relative densities for optimized process parameter set.

\begin{tabular}{cccccc}
\hline $\begin{array}{c}\text { Beam } \\
\text { Current }\end{array}$ & $\begin{array}{c}\text { Scan } \\
\text { Speed }\end{array}$ & $\begin{array}{c}\text { Focus } \\
\text { Offset }\end{array}$ & $\begin{array}{c}\text { Line } \\
\text { Offset }\end{array}$ & $\begin{array}{c}\text { Layer } \\
\text { Thickness }\end{array}$ & $\begin{array}{c}\text { Relative } \\
\text { Density }\end{array}$ \\
\hline $15 \mathrm{~mA}$ & $4000 \mathrm{~mm} / \mathrm{s}$ & $3 \mathrm{~mA}$ & $0.1 \mathrm{~mm}$ & $70 \mu \mathrm{m}$ & $99.90 \% \pm 0.04 \%$ \\
\hline
\end{tabular}

The parameters were validated for six cubic specimens $(10 \mathrm{~mm} \times 10 \mathrm{~mm} \times 14 \mathrm{~mm})$, which exhibited even top surfaces and low porosity. A metallographic cross-section of one of those specimens is shown in Figure 5 along with the microstructure evaluated by means of SEM imaging.
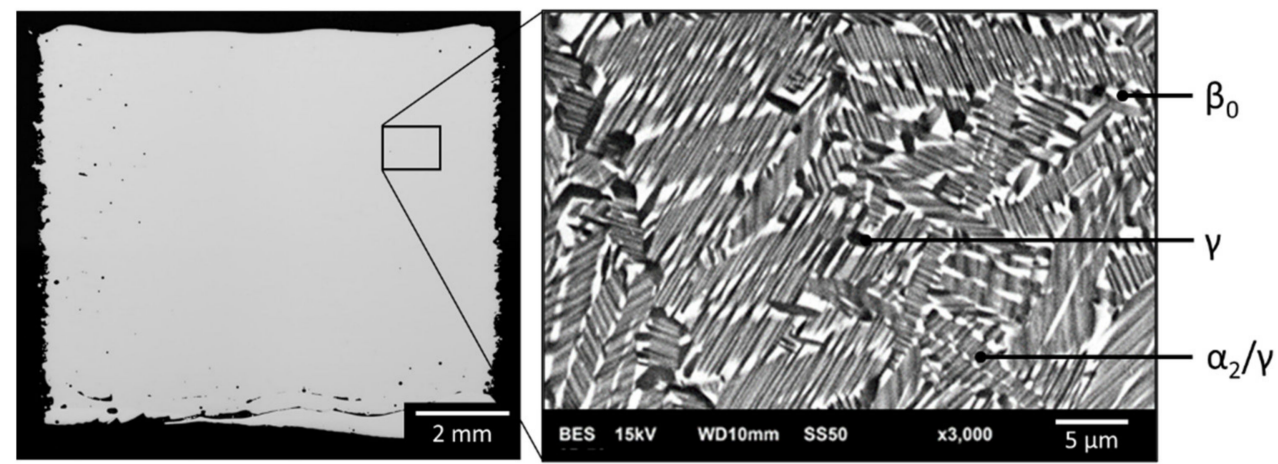

Figure 5. Cross-sectional image and scanning electron microscopy (SEM) image of microstructure of a sample manufactured using the optimized parameter set.

Only few defects are visible in the cross-section, most of which are spherical and can therefore be assigned to gas porosity [3]. Gas porosity cannot fully be avoided within the EB-PBF process, but can be almost completely eliminated through a subsequent hot isostatic pressing step [7]. Three phases can be distinguished in the microstructural image: The $\alpha_{2}-/ \gamma$-colonies can be recognized by their lamellar structure. The $\gamma$-phase also occurs in the form of globular grains, which appear in a dark gray color in the SEM image. The bright areas can be assigned to the $\beta_{0}$-phase [13], which in this case apparently forms a seam at the grain boundaries.

EBSD investigations were performed on cross sections taken out parallel to the building direction of a specimen manufactured with the optimized manufacturing parameter set. The phases given in Table 3 were used according to the phase definition in this table. 
Table 3. Crystallographic properties and amount of the detected phases using electron backscatter diffraction (EBSD); specimen fabricated with optimized parameters.

\begin{tabular}{|c|c|c|c|c|c|c|c|c|c|}
\hline \multirow{2}{*}{ Phase } & \multirow{2}{*}{$\begin{array}{c}\text { Phase } \\
\text { Fraction/\% }\end{array}$} & \multirow{2}{*}{$\begin{array}{c}\text { Phase Fraction } \\
\text { Corr. } / \%\end{array}$} & \multicolumn{7}{|c|}{ Phase Definition $[29,30]$} \\
\hline & & & $\mathrm{a} / \AA \AA$ & b/Å & c/Å & Alpha/ ${ }^{\circ}$ & Beta $/^{\circ}$ & Gamma/ ${ }^{\circ}$ & Spacegroup \\
\hline $\begin{array}{c}\text { TiAl- } \\
\text { gamma } / \gamma- \\
\text { phase }\end{array}$ & 73.97 & 89.38 & 4.05 & 4.05 & 4.13 & 90 & 90 & 90 & 123 \\
\hline $\begin{array}{l}\text { Titanium- } \\
\text { Cubic/ } \beta- \\
\text { phase }\end{array}$ & 5.57 & 6.73 & 3.31 & 3.31 & 3.31 & 90 & 9 & 90 & 229 \\
\hline $\begin{array}{l}\mathrm{Ti}_{3} \mathrm{Al}- \\
\text { alpha2 } / \alpha_{2}- \\
\text { phase }\end{array}$ & 2.44 & 3.89 & 5.78 & 5.78 & 4.65 & 90 & 90 & 120 & 194 \\
\hline $\begin{array}{l}\text { Titanium- } \\
\text { Hexagonal/ } \alpha- \\
\text { phase }\end{array}$ & 0.78 & - & 2.95 & 2.95 & 4.68 & 90 & 90 & 120 & 194 \\
\hline $\begin{array}{c}\text { Zero } \\
\text { solution }\end{array}$ & 17.24 & - & - & - & - & - & - & - & - \\
\hline
\end{tabular}

The scanning parameters are shown in Figure 6b. The EBSD band contrast map shows the deformation-free microstructure. The pattern from the grain and especially on the phase boundaries have no solution, and are shown in dark gray in the band contrast band and black in the phase map. This allows us to clearly distinguish between the phase and the grain boundaries. The grain size is less than $4 \mu \mathrm{m}$ with standard size distribution. Due to high acceleration voltage and resulting beam spot of about $30 \mathrm{~nm}$, the $\alpha_{2}$ lamellae, which can be seen clearly in the SEM image in Figure 5, can only be resolved sporadically in the EBSD maps. Figure $6 \mathrm{c}$ shows the amount and distribution of the different phases. The $\gamma$-phase occupies the largest area, whereby the $\alpha_{2}$ lamellae in the $\alpha_{2} / \gamma$-colonies can only be observed sporadically. The $\beta$-phase is localized at the grain boundaries, as already observed in the SEM images. Given the similarity with the crystallographic parameter of $\alpha_{2}$-phase and $\alpha$-phase, it was not possible to distinguish clearly between those two phases from the same crystallographic space group. Since the presence of the $\alpha$-phase is improbable, its indication can be considered as incorrect.

The phase distribution can be seen in Table 3. After taking into consideration the zero solution on the phase boundaries, it can be estimated that almost $90 \%$ is covered by the $\gamma$-phase. The $\beta$-phase takes up $6.73 \%$ of the area, the indicated fraction of $\alpha_{2}-/ \alpha$-phase reaches $3.89 \%$.

In Figure 7, the relative densities and the maximum pore diameters obtained from the metallographic cross-sections are plotted against the volumetric energy density $E_{V}$.

Figure 7 clearly shows an improvement in relative density with increasing volume energy density, while at the same time the size of the pores in the material decreases. This is in line with the predictions from the regression model presented earlier in this study. Reasonable part densities of more than $99.5 \%$ with only small pores could be achieved using volumetric energy densities above $20 \mathrm{~J} / \mathrm{mm}^{3}$. Nevertheless, the majority of specimens fabricated within this range of energy input still exhibit porous or slightly porous top surfaces, which might be an indicator of defects due to a lack of fusion. On the other hand, applying volumetric energy densities of more than $40 \mathrm{~J} / \mathrm{mm}^{3}$ almost certainly lead to parts with negligible porosity, but swelling was a frequently encountered problem. The optimized parameter set (see Table 2) with an $E_{V}$ of $32.1 \mathrm{~J} / \mathrm{mm}^{3}$ apparently provides a good compromise between part density and surface quality. Nevertheless, the occurrence of the different categories for top surface qualities across a wide range of volumetric energy densities indicates that choosing a certain value for $E_{V}$ cannot be seen as a guarantee for obtaining an even top surface. 
(a)

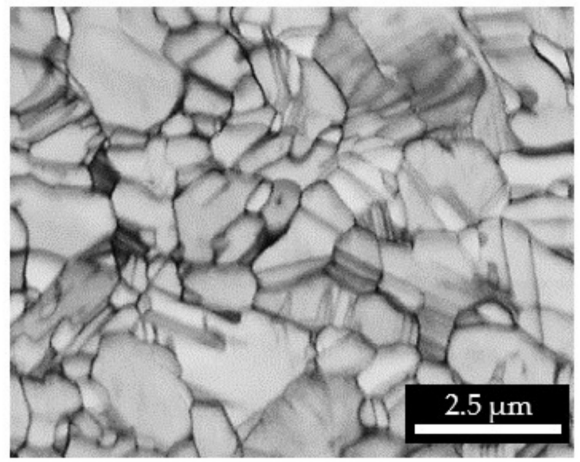

(c)

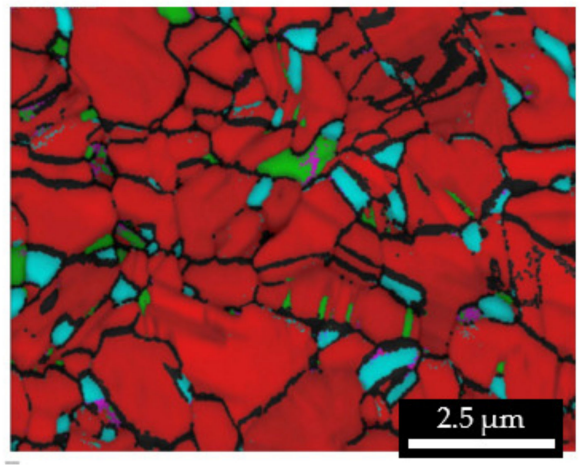

(b) Voltage: $20 \mathrm{kV}$

Magnification: $5000 \times$

Sample tilting: $70^{\circ}$

Working distance: $15.8 \mathrm{~mm}$

Step size: $25 \mathrm{~nm}$

Figure 6. EBSD-maps (optimized process parameters), parallel to building direction. (a) EBSD band contrast map; (b) scan parameters; (c) EBSD phase map.
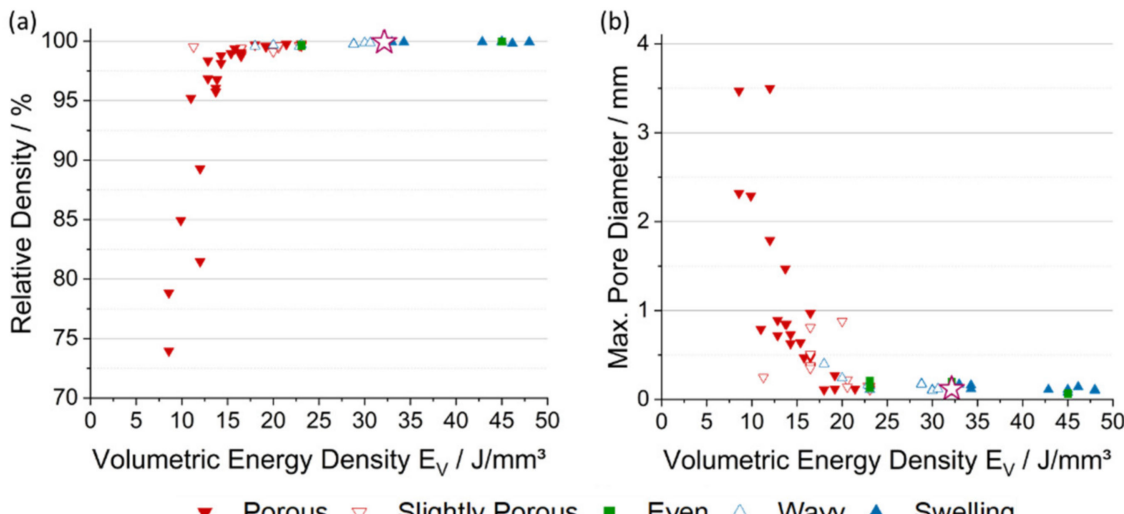

Figure 7. (a) Relative densities and (b) maximum pore diameters for different electron beam powder bed fusion (EB-PBF) volumetric energy densities classified by sample top surface qualities. The optimized parameter set is marked with a star symbol.

\subsection{Surface Characterization}

The correlation between EB-PBF process parameters and top surface roughness was investigated by means of laser scanning confocal microscopy. The areal surface parameters arithmetical mean height $S a$ and texture aspect ratio Str depending on the volumetric energy density are presented in Figure 8, while Figure 9 shows confocal microscopic images of surfaces attained with different sets of process parameters. The arithmetical mean height $S a$ is defined as the arithmetic mean of the absolute of the ordinate values within the measuring area. The texture aspect ratio Str characterizes the ratio between the horizontal distance in which the autocorrelation function shows the fastest decay to a predefined value $s$ and the horizontal distance in which the autocorrelation function has the slowest decay to the value $s$, and thus describes the uniformity of the surface texture [31]. 

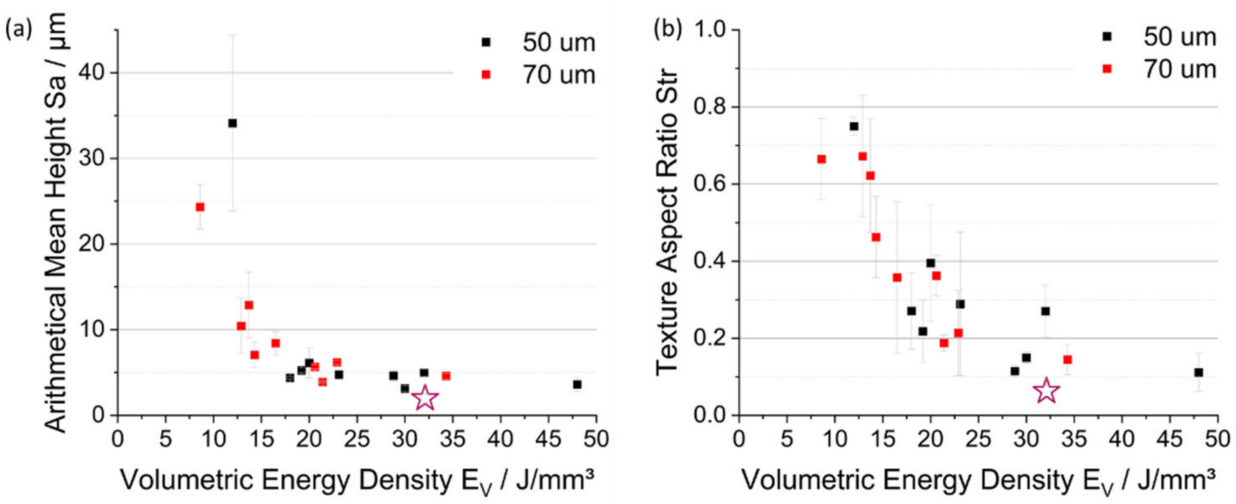

Figure 8. (a) Arithmetical mean height $S a$ and (b) texture aspect ratio $S t r$ measured by means of confocal laser scanning microscopy for different EB-PBF volumetric energy densities. The optimized parameter set is marked with a star symbol.
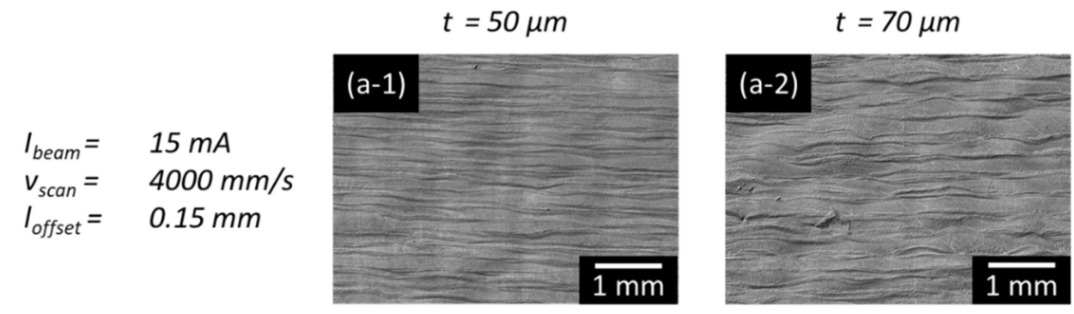
$I_{\text {beam }}=10 \mathrm{~mA}$
$v_{\text {scan }}=4000 \mathrm{~mm} / \mathrm{s}$
$I_{\text {offset }}=0.25 \mathrm{~mm}$
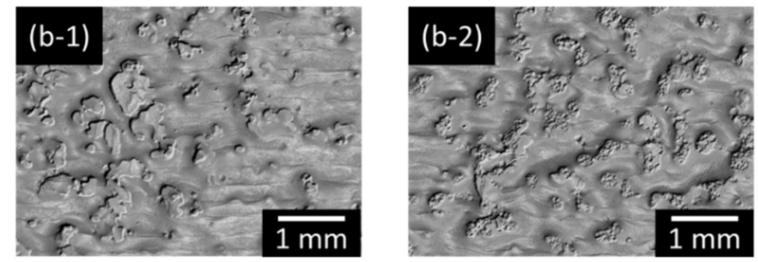
$I_{\text {beam }}=15 \mathrm{~mA}$
$v_{\text {scan }}=2500 \mathrm{~mm} / \mathrm{s}$
$I_{\text {offset }}=0.25 \mathrm{~mm}$
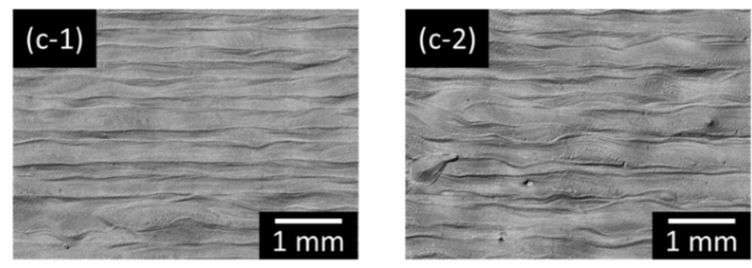

$I_{\text {beam }}=15 \mathrm{~mA}$
$v_{\text {scan }}=4000 \mathrm{~mm} / \mathrm{s}$
$I_{\text {offset }}=0.25 \mathrm{~mm}$
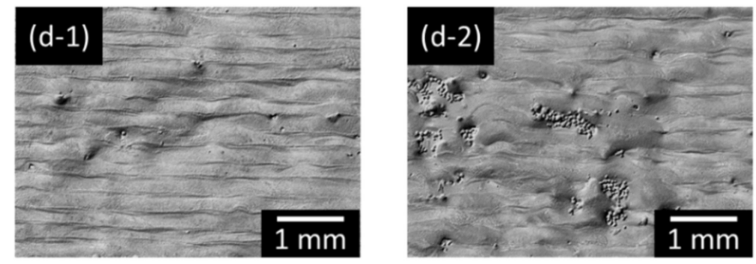

$$
\begin{aligned}
& I_{\text {beam }}=15 \mathrm{~mA} \\
& V_{\text {scan }}=4000 \mathrm{~mm} / \mathrm{s} \\
& I_{\text {offset }}=0.10 \mathrm{~mm}
\end{aligned}
$$

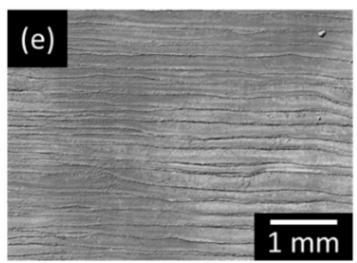

Figure 9. Top surface images obtained by means of confocal laser scanning microscopy. The samples were manufactured using the parameters specified on the left-hand side with a layer thickness of $50 \mu \mathrm{m}(\mathbf{a}-\mathbf{1}-\mathbf{d}-\mathbf{1})$ or $70 \mu \mathrm{m}(\mathbf{a}-\mathbf{2}-\mathbf{e})$, respectively. The sample surface obtained using the optimized parameter set is shown in (e). 
A substantial reduction in arithmetical mean height $S a$ can be observed with increasing energy density. Values below $5 \mu \mathrm{m}$ for $S a$ could generally be achieved with volumetric energy densities above $25 \mathrm{~J} / \mathrm{mm}^{3}$. The overall lowest surface roughness could be obtained with the optimized parameter set. A similar trend was found for the texture aspect ratio Str. Although the individual values exhibit a rather large standard deviation, the decrease in $S t r$ with increasing $E_{V}$ is still evident. Again, the minimum value was measured for the specimens manufactured with the optimized EB-PBF parameters. It may seem surprising that the roughness did not increase for high volumetric energy densities due to swelling effects. However, it should be noted that surface roughness was characterized on larger specimens with a cross-sectional area of $23 \mathrm{~mm} \times 23 \mathrm{~mm}$, compared to a top surface area of $10 \mathrm{~mm} \times 10 \mathrm{~mm}$ for the samples used for metallographic investigation. Thus, the length of the scan vector was increased, thus also increasing beam return time and lowering the risk of swelling.

An Str value below 0.1 indicates that those sample surfaces exhibit a pronounced anisotropic character. This is in good agreement with the largely undisturbed, parallel aligned melt tracks of the even top surfaces as shown in Figure 9e. In contrast to that, the Str values at lower volumetric energy densities suggest more isotropic surface morphologies. This becomes apparent from Figure 9(b-1,b-2), respectively. Both images are illustrative for surfaces fabricated with a low energy input. No consistent melt tracks are visible. Instead, areas of molten material and voids with unmelted powder particles can be distinguished.

In each row in Figure 9, the top surface morphologies of specimens produced with different layer thicknesses with otherwise identical parameter settings are compared. The exception is the optimized parameter set in Figure 9e, which was manufactured exclusively with a layer thickness of $70 \mu \mathrm{m}$. In general, a deterioration in surface quality can be seen for higher layer thicknesses, probably due to the reduction in total energy input. This is most obvious for Figure 9(d-1,d-2). Figure 9(d-1) shows some voids and inclusions of not completely melted particles, whereas Figure $9(\mathrm{~d}-2)$ exhibits considerably larger areas with incomplete melting. Top surface quality can significantly be improved with a higher overlapping of the individual melt tracks by reducing the line offset, as can be seen in Figure 9(a-1,a-2) for both layer thicknesses. Comparing the images in Figure 9(d-1,d-2) with those in Figure $9(\mathrm{c}-1, \mathrm{c}-2)$, it is apparent that reducing the scan speed from $4000 \mathrm{~mm} / \mathrm{s}$ to $2500 \mathrm{~mm} / \mathrm{s}$ could also help to eliminate part of the surface pores, although distortions at the melt track boundaries as well as inclusions are still noticeable.

\subsection{Aluminum Loss}

The aluminum content was determined by means of EDX measurements to allow a qualitative comparison among the specimens. The results are plotted in Figure 10 against the volumetric energy density. The aluminum content of the original TNM-B1 powder raw material was determined via EDX measurements on metallographic particle cross-sections and is shown as a benchmark in Figure 10.

According to the quasi-binary Ti-xAl-4Nb-1Mo-0.1B phase diagram [32], the TNMB1 alloy solidifies peritectically for aluminum contents above approximately 45.5 at. $\%$, whereas for lower aluminum contents, solidification occurs through the $\beta$-phase [7]. This boundary is marked by a horizontal dashed line in Figure 10. Overall, an almost linear trend for the aluminum loss with increasing volumetric energy densities was observed. The optimized parameter set exhibited an aluminum content of $43.7 \pm 0.6$ at. $\%$, which is close to the aluminum content of conventionally manufactured TNM-B1 components. Accordingly, it can be expected that the solidification takes place via the $\beta$-phase.

Figure 11 depicts representative microstructures of three specimens, which were manufactured with different volumetric energy densities and thus differ in their aluminum contents. 


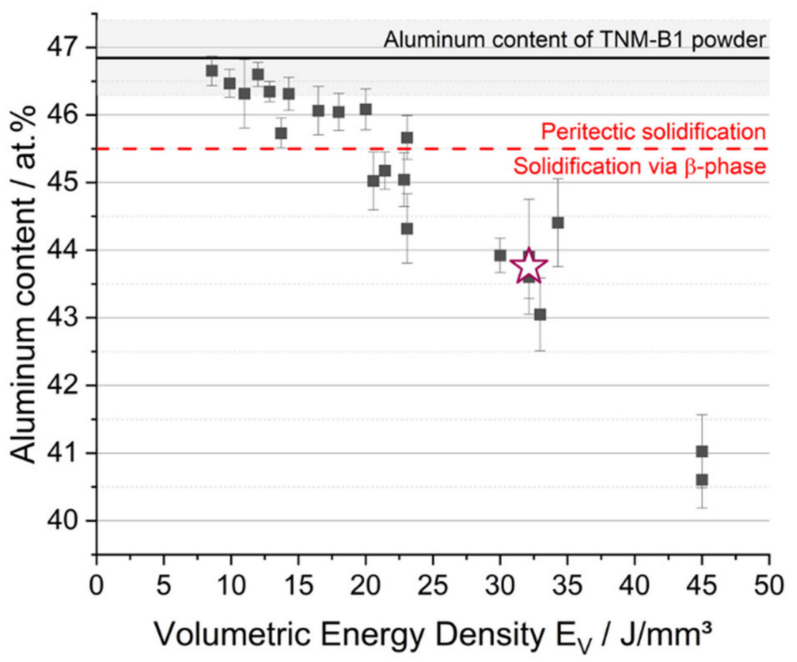

Figure 10. Aluminum content of samples manufactured with different EB-PBF volumetric energy densities in comparison to the powder raw material determined via EDX analysis. The dashed line marks the transition between a peritectic solidification behavior and a solidification via the single $\beta$-phase field according to the Ti-xAl-4Nb-1Mo-0.1B phase diagram [7,32]. The optimized parameter set is marked with a star symbol.

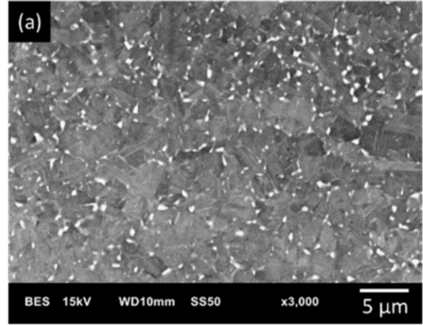

$E_{V}=12.9 \mathrm{~J} / \mathrm{mm}^{3}$

$46.3 \pm 0.1$ at. $\% \mathrm{Al}$

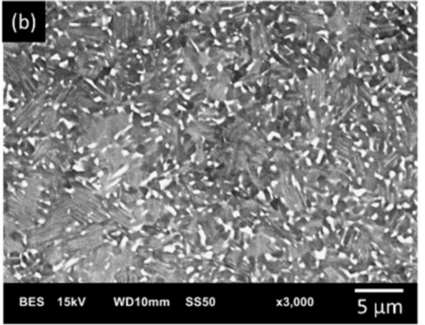

$E_{V}=22.9 \mathrm{~J} / \mathrm{mm}^{3}$

$45.0 \pm 0.4$ at.\% Al

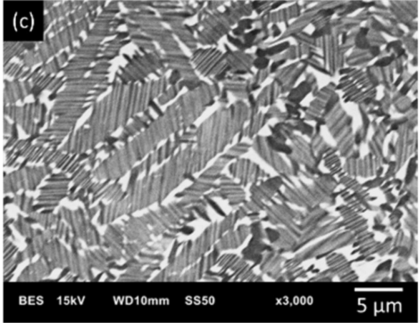

$E_{V}=34.3 \mathrm{~J} / \mathrm{mm}^{3}$

$44.4 \pm 0.6$ at.\% $\mathrm{Al}$

Figure 11. SEM images of microstructures on metallographic cross-sections. Volumetric energy density for manufacturing increases and aluminum content decreases from $(\mathbf{a}-\mathbf{c})$.

The images suggest that both grain size and lamellar spacing increase with increasing energy input. At the same time, the $\beta_{0}$-phase fraction also seems to increase and shows a tendency to form fringes at the grain boundaries. The microstructure in Figure 11c is similar to that obtained with the optimized parameter set with a volumetric energy density of $32.1 \mathrm{~J} / \mathrm{mm}^{3}$ as shown in Figure 5 . Overall, the results indicate that the microstructure is highly sensitive to the applied EB-PBF process parameters and to changes in the aluminum content.

\section{Discussion}

Within the framework of this study, a suitable process parameter window for defectfree processing of an aluminum-enriched TNM-B1 alloy powder via EB-PBF should be determined. For this purpose, a statistical central composite design was applied to evaluate the effect of each process parameter on part density and to narrow down a suitable set of parameters. The results indicate that the overall porosity can be reduced when a higher beam current, a slower scan speed, a lower line offset, and a lower layer thickness are chosen. This seems plausible since all of those adjustments are associated with an increased energy input (see Equation (5)), thus reducing defects due to a lack of fusion [3,9]. Among the parameters investigated, beam current and line offset were found to have the strongest 
impact on part density. Numerical simulations could show that smaller melt pools are created when lower beam currents are applied [33]. This might lead to incomplete melting of the powder particles and lack of fusion. The effect of the line offset is illustrated in Figure 12: At an optimal line offset, the two neighboring melt tracks exhibit a sufficient degree of overlapping. When the line offset and thus the distance between the adjacent hatch lines exceed a critical value, the particles between both melt tracks may not be fully melted, leading to porosity in the final part [28].
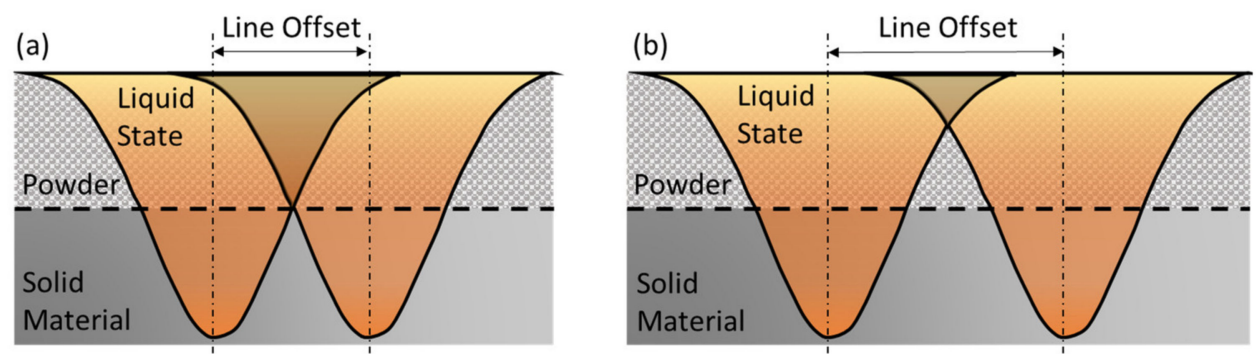

Figure 12. Schematic illustration of overlapping of two adjacent melt tracks at (a) optimal line offset and (b) too large line offset (adapted from [28]).

The findings of the response surface analysis are mostly supported by a study by Gong et al. [28], who investigated the influence maximum beam current, line offset, focus offset, and speed function index on the porosity of EB-PBF manufactured Ti-6Al-4V components by means of analysis of variance (ANOVA). Analogous to our observations, the authors report an increase in density with increasing maximum beam current, lower line offsets, and a lower speed function index, which corresponds to a reduction in scan speed [11]. In contradiction to our results, the focus offset was also found to be a significant influencing factor in terms of porosity. A small focus offset leads to small beam diameters and high melting depths, while a larger value is associated with broader and shallower melt pools. Nevertheless, the researchers outline that the effect is only noticeable at focus offset values above $16 \mathrm{~mA}$ [28]. Therefore, it is assumed that the focus offset values chosen for the design of experiments in this study (see Table 1) did not show sufficient variation to lead to a significant difference in relative density.

While the regression model may provide evidence for the lower limit of the processing window to avoid misconnections, it does not include any information regarding its upper limit, which is defined by the occurrence of swelling as a consequence of excessive energy input [7]. Swelling is often described as the results of uneven melt flow and material relocation, which may be caused by the interplay of the surface tension of the melt and the vapor back pressure due to evaporation of volatile elements $[7,8]$. For this reason, the top surface qualities were also taken into account as a criterion for selecting an optimal set of parameters.

Material consolidation during EB-PBF is to a great extent governed by surface tension effects [34]. Consequently, the formation of the melt track morphology is largely determined by the wetting of the molten material on the adjacent solid powder particles [11,34]. The effect of insufficient energy input is particularly apparent from the surface in Figure $9(b-1, b-2)$ in comparison to samples created with a higher beam current. Here, the low energy density might have impeded sufficient remelting and wetting on the previous layer, while a connection to the adjacent melt tracks could have been hampered due to the high line offset. Hence, the surface tension may have caused the molten material to form accumulations on the surface, leading to discontinuous melt tracks [28] and the observed high surface roughness (see Figure 8) [35]. Surface tension and flow behavior inside the melt pool depend on temperature and thermal gradients [34]. The size and shape of the melt pool are highly dynamic and strongly affected by process parameters and the distribution of surrounding powder particles $[34,36]$. Therefore, it seems plausible that the melt in the vicinity of defects and particle inclusions was disturbed, as suggested by the 
images in Figure 9(c-2,d-1,d-2). Surface defects can also be a consequence of fluctuations in the melt pool due to a horizontal movement of the melt at higher energy inputs [34], which could explain the wavy appearance of the sample top surfaces at elevated energy densities [20]. In contrast to that, the comparatively smooth surfaces with equally aligned melt tracks obtained for the optimized parameter set (see Figures 8 and 9e) might indicate a rather stable melt pool behavior.

Figure 10 shows a substantial aluminum loss with increasing volumetric energy densities. This is in good agreement with results obtained by Zhou et al. [18], who reported a dramatic increase in aluminum evaporation during EB-PBF of Ti-47Al-2Cr-2Nb with increasing areal energy density. The preferential evaporation of aluminum has its origin in the significantly higher vapor pressure at process temperatures in comparison to titanium and is aggravated with increasing temperature [18,36]. Klassen et al. [36] predicted peak temperatures of $3300{ }^{\circ} \mathrm{C}$ to $3400{ }^{\circ} \mathrm{C}$ for EB-PBF of Ti-48Al-2Cr-2Nb for line energies of $150 \mathrm{~J} / \mathrm{m}$ based on numerical simulations. Since the line energy of the optimized parameter set in our study equaled $225 \mathrm{~J} / \mathrm{m}$, it can be assumed that the peak temperatures during processing even exceeded those predicted values. Several studies have confirmed that aluminum loss is mainly linked to the line energy $E_{L}[7,20,27,36]$, most likely due to higher occurring temperatures and larger melt pool sizes [27].

A change in aluminum content shifts the $\gamma$-solvus-temperature according to the phase diagram, which in turn affects the heat treatment temperatures required to achieve desired microstructural properties [10]. Furthermore, excessive aluminum evaporation often leads to inhomogeneous microstructures [13]. One reason might be that, according to several studies, aluminum preferentially evaporates near the top of the melt pool, resulting in differences in the aluminum content across the melt track cross-section $[21,36,37]$. These compositional inhomogeneities may impact the mechanical properties [21] and should therefore be avoided [3,7]. One possibility for minimizing aluminum loss could be an adjustment of the process parameters applied in EB-PBF. For instance, Klassen et al. [36] suggested that increasing the scan speed while at the same decreasing the line offset to maintain a constant energy density could reduce evaporation. Another option could be an overall reduction in energy input, however, this would be associated with a sacrifice in part density $[3,36]$. The approach pursued in this study was to increase the percentage of aluminum in the powder raw material in order to compensate for evaporation losses during the process. The measurements presented in Figure 10 provide strong evidence that the nominal composition of the TNM-B1 alloy, which contains approximately 43.5 at. $\%$ aluminum, could successfully be attained when using the optimized EB-PBF parameter set.

The SEM images displayed in Figure 11 indicate an interrelation between process parameters and aluminum content and the resulting microstructures. According to the quasi-binary Ti-Al phase diagram, a peritectic solidification reaction can be expected for aluminum contents above 45.5 at.\% [7]. A peritectic solidification pathway could be beneficial as it favors isotropic microstructures with no pronounced textures during rapid cooling [7,38]. When the aluminum content is decreased below 45.5 at.\%, e.g., as a consequence of evaporation, the amount of $\gamma$-phase is decreased and a single $\beta$-phase field is opened up at high temperatures [7]. Due to the steep temperature gradients in EB-PBF, these $\beta$-solidifying alloys mostly exhibit a directional growth of the $\beta$-grains along the build direction [13], which often stretch across several layers [3]. As a result of the recurrent heat input, the elevated processing temperatures in EB-PBF, and solid-state phase transformations during cooling, the room temperature microstructures are often characterized by a pronounced fiber texture of the $\beta_{0}$-phase in the $<001>$ direction $[7,10,13]$. High energy density and low preheating temperatures during manufacturing were found to further enhance grain texture [7].

In the microstructural images in Figure 11, the increase in anisotropy and the volume fraction of $\beta_{0}$-phase with increased energy inputs and declining aluminum contents is clearly visible. This observation is in line with the findings by other researchers as described above. The optimized parameter set also exhibits a distinctive texture of the $\beta_{0}$-phase and 
a wide lamellar spacing within the $\alpha_{2}-/ \gamma$-regions (see Figure 5). The proportion of $\gamma$-phase according to EBSD measurements is very high at almost $90 \%$ compared to $\beta$ - and $\alpha_{2}$ phase (see Table 3). Although the mechanical properties still need to be addressed in future research activities, the observed microstructure is believed to be particularly detrimental in terms of ductility because of the brittle behavior of the $\beta_{0}$-phase [3,7]. Moreover, a strong dependency of the mechanical properties on the build-up direction is expected. To further characterize the mechanical properties, especially ductility at different test temperatures, quasi-static tensile tests and fatigue tests at room temperature and high temperature should be performed in the future. One possibility for achieving a more favorable microstructure might be an adjustment of the process parameters in such a way that a peritectic solidification is enabled. However, comparing Figures 7 and 10, it should be noted that using volumetric energy densities at which the aluminum loss is low enough to allow peritectic solidification would most likely result in significant porosity in the component. For this reason, the investigation of suitable heat treatments for tailored microstructures will be a key aspect of future research.

\section{Conclusions and Outlook}

The objective of this study was to thoroughly investigate the influence of electron beam powder bed fusion (EB-PBF) process parameters on the processability of the titanium aluminide alloy TNM-B1 (Ti-43.5Al-4Nb-1Mo-0.1B). For this purpose, a central composite design was created to evaluate the effect of beam current, scan speed, line offset, focus offset and layer thickness on the resulting part density. Beam current and line offset were identified as the most influential factors in terms of relative density, whereas the focus offset had no significant impact within the investigated parameter range. Not surprisingly, it was found that porosity could generally be reduced when higher volumetric energy densities were applied in the process. However, the maximum energy input is limited due to the occurrence of swelling. Taking both the results from the regression analysis and the top surface qualities into account, a parameter set which was optimized for obtaining high relative densities and smooth top surfaces could be derived. Thus, relative densities of 99.9\% could be achieved.

Moreover, the influence of volumetric energy density on top surface roughness and aluminum loss was investigated. The findings can be summarized as follows:

1. Both the arithmetical mean height $S a$ and the texture aspect ratio $S t r$ decrease with increasing energy input. This observation could be linked to the top surface topography, which exhibited inhomogeneous, discontinuous melt tracks at insufficient energy densities, while evenly aligned hatch lines were visible in the case of the optimized parameter set.

2. The aluminum content substantially decreases with increasing volumetric energy densities. In order to compensate for the expected aluminum evaporation during the process, the raw material was alloyed with an excess of approximately 3 at.\% aluminum in comparison to the nominal composition of the TNM-B1 alloy powder. Using the optimized parameter set for EB-PBF, the resulting aluminum content after the process amounted to $43.7 \pm 0.6$ at. $\%$, which was in good agreement with the chemical composition of conventionally processed TNM-B1.

3. The resulting microstructures are apparently highly sensitive to the applied process parameters and the associated aluminum evaporation. With increasing energy input, an increase in the amount of $\beta_{0}$-phase and a wide lamellar spacing in the $\alpha_{2}-/ \gamma$-colonies were observed. Although the mechanical properties are yet to be investigated, a rather brittle behavior is expected as a consequence of this microstructural composition. Hence, future research will address the evaluation of appropriate heat-treatment strategies. In addition, quasi-static and cyclic investigations will be performed to characterize the different material states. 
Author Contributions: Conceptualization, J.M. and M.T.; methodology, J.M. and M.T.; software, J.M.; validation, J.M.; formal analysis, J.M.; investigation, J.M. and M.T.; resources, J.M.; data curation, J.M. and M.T.; writing—original draft preparation, J.M. and M.T.; writing—review and editing, M.T., A.M., L.S., E.L., F.B., M.M.B., F.W. and C.L.; visualization, J.M.; supervision, A.M., F.W. and C.L.; project administration, F.W. and C.L..; funding acquisition, F.W. and C.L. All authors have read and agreed to the published version of the manuscript.

Funding: This research was funded by the German Research Foundation (Deutsche Forschungsgemeinschaft (DFG)) under the grant number 404665753. Furthermore, the authors thank the German Research Foundation for funding the "Focused Ion Beam Scanning Electron Microscope" (INST 212/402-1 FUGG) at TU Dortmund University.

Institutional Review Board Statement: Not applicable.

Informed Consent Statement: Not applicable.

Data Availability Statement: The data presented in this study are available on request from the corresponding author.

Acknowledgments: We would like to thank Julius Hendl and Stefan Enghardt for the fruitful discussions.

Conflicts of Interest: The authors declare no conflict of interest.

\section{References}

1. Clemens, H.; Mayer, S. Design, Processing, Microstructure, Properties, and Applications of Advanced Intermetallic TiAl Alloys. Adv. Eng. Mater. 2013, 15, 191-215. [CrossRef]

2. Clemens, H.; Mayer, S. Intermetallic titanium aluminides in aerospace applications-Processing, microstructure and properties. Mater. High Temp. 2016, 33, 560-570. [CrossRef]

3. Reith, M.; Franke, M.; Schloffer, M.; Körner, C. Processing 4th generation titanium aluminides via electron beam based additive manufacturing-Characterization of microstructure and mechanical properties. Materialia 2020, 14, 100902. [CrossRef]

4. Appel, F.; Paul, D.H.; Oehring, M. Gamma Titanium Aluminide Alloys; Science and Technology, WILEY-VCH Verlag GmbH \& Co. KGaA: Weinheim, Germany, 2011.

5. Pflumm, R.; Donchev, A.; Mayer, S.; Clemens, H.; Schütze, M. High-temperature oxidation behavior of multi-phase Mo-containing $\gamma$-TiAl-based alloys. Intermetallics 2014, 53, 45-55. [CrossRef]

6. Schloffer, M.; Rashkova, B.; Schöberl, T.; Schwaighofer, E.; Zhang, Z.; Clemens, H.; Mayer, S. Evolution of the wo phase in a $\beta$-stabilized multi-phase TiAl alloy and its effect on hardness. Acta Mater. 2014, 64, 241-252. [CrossRef]

7. Wimler, D.; Lindemann, J.; Reith, M.; Kirchner, A.; Allen, M.; Vargas, W.G.; Franke, M.; Klöden, B.; Weißgärber, T.; Güther, V.; et al. Designing advanced intermetallic titanium aluminide alloys for additive manufacturing. Intermetallics 2021, 131, 107109. [CrossRef]

8. Körner, C. Additive manufacturing of metallic components by selective electron beam melting-A review. Int. Mater. Rev. 2016, 61,361-377. [CrossRef]

9. Juechter, V.; Franke, M.M.; Merenda, T.; Stich, A.; Körner, C.; Singer, R.F. Additive manufacturing of Ti-45Al-4Nb-C by selective electron beam melting for automotive applications. Addit. Manuf. 2018, 22, 118-126. [CrossRef]

10. Mayer, S.; Schimbäck, D.; Wartbichler, R.; Wimler, D.; Clemens, H. Metallography of Intermetallic Titanium Aluminides-The (Additive) Manufacturing Makes the Difference. Pract. Metallogr. 2019, 56, 567-584. [CrossRef]

11. Galati, M.; Iuliano, L. A literature review of powder-based electron beam melting focusing on numerical simulations. Addit. Manuf. 2018, 19, 1-20. [CrossRef]

12. DebRoy, T.; Wei, H.L.; Zuback, J.S.; Mukherjee, T.; Elmer, J.W.; Milewski, J.O.; Beese, A.M.; Wilson-Heid, A.; De, A.; Zhang, W. Additive manufacturing of metallic components-Process, structure and properties. Prog. Mater. Sci. 2018, 92, 112-224. [CrossRef]

13. Wartbichler, R.; Clemens, H.; Mayer, S. Electron Beam Melting of a $\beta$-Solidifying Intermetallic Titanium Aluminide Alloy. Adv. Eng. Mater. 2019, 21, 1900800. [CrossRef]

14. Cormier, D.; Harrysson, O.; Mahale, T.; West, H. Freeform Fabrication of Titanium Aluminide via Electron Beam Melting Using Prealloyed and Blended Powders. Res. Lett. Mater. Sci. 2007, 2007, 1-4. [CrossRef]

15. Murr, L.E.; Gaytan, S.M.; Ceylan, A.; Martinez, E.; Martinez, J.L.; Hernandez, D.H.; Machado, B.I.; Ramirez, D.A.; Medina, F.; Collins, S. Characterization of titanium aluminide alloy components fabricated by additive manufacturing using electron beam melting. Acta Mater. 2010, 58, 1887-1894. [CrossRef]

16. Chen, Y.; Yue, H.; Wang, X. Microstructure, texture and tensile property as a function of scanning speed of Ti-47Al-2Cr-2Nb alloy fabricated by selective electron beam melting. Mater. Sci. Eng. A 2018, 713, 195-205. [CrossRef]

17. Yue, H.; Chen, Y.; Wang, X.; Kong, F. Effect of beam current on microstructure, phase, grain characteristic and mechanical properties of Ti-47Al-2Cr-2Nb alloy fabricated by selective electron beam melting. J. Alloys Compd. 2018, 750, 617-625. [CrossRef] 
18. Zhou, J.; Li, H.; Yu, Y.; Li, Y.; Qian, Y.; Firouzian, K.; Lin, F. Research on aluminum component change and phase transformation of TiAl-based alloy in electron beam selective melting process under multiple scan. Intermetallics 2019, 113, 106575. [CrossRef]

19. Biamino, S.; Penna, A.; Ackelid, U.; Sabbadini, S.; Tassa, O.; Fino, P.; Pavese, M.; Gennaro, P.; Badini, C. Electron beam melting of Ti-48Al-2Cr-2Nb alloy: Microstructure and mechanical properties investigation. Intermetallics 2011, 19, 776-781. [CrossRef]

20. Schwerdtfeger, J.; Körner, C. Selective electron beam melting of Ti-48Al-2Nb-2Cr: Microstructure and aluminium loss. Intermetallics 2014, 49, 29-35. [CrossRef]

21. Todai, M.; Nakano, T.; Liu, T.; Yasuda, H.Y.; Hagihara, K.; Cho, K.; Ueda, M.; Takeyama, M. Effect of building direction on the microstructure and tensile properties of Ti-48Al-2Cr-2Nb alloy additively manufactured by electron beam melting. Addit. Manuf. 2017, 13, 61-70. [CrossRef]

22. Tang, H.P.; Yang, G.Y.; Jia, W.P.; He, W.W.; Lu, S.L.; Qian, M. Additive manufacturing of a high niobium-containing titanium aluminide alloy by selective electron beam melting. Mater. Sci. Eng. A 2015, 636, 103-107. [CrossRef]

23. Bieske, J.; Franke, M.; Schloffer, M.; Körner, C. Microstructure and properties of TiAl processed via an electron beam powder bed fusion capsule technology. Intermetallics 2020, 126, 106929. [CrossRef]

24. Siebertz, K.; van Bebber, D.; Hochkirchen, T. Statistische Versuchsplanung; Springer: Berlin/Heidelberg, Germany, 2010; ISBN 9783-642-05492-1. [CrossRef]

25. Beraud, N.; Vignat, F.; Villeneuve, F.; Dendievel, R. Improving dimensional accuracy in EBM using beam characterization and trajectory optimization. Addit. Manuf. 2017. [CrossRef]

26. Kurzynowski, T.; Madeja, M.; Dziedzic, R.; Kobiela, K. The Effect of EBM Process Parameters on Porosity and Microstructure of Ti-5Al-5Mo-5V-1Cr-1Fe Alloy. Scanning 2019. [CrossRef] [PubMed]

27. Juechter, V.; Scharowsky, T.; Singer, R.F.; Körner, C. Processing window and evaporation phenomena for Ti-6Al-4V produced by selective electron beam melting. Acta Mater. 2014, 76, 252-258. [CrossRef]

28. Gong, H.; Rafi, K.; Starr, T.; Stucker, B. The Effects of Processing Parameters on Defect Regularity in Ti-6Al-4V Parts Fabricated By Selective Laser Melting and Electron Beam Melting. In Proceedings of the 24th Annual International Solid Freeform Fabrication Symposium-An Additive Manufacturing Conference, Austin, TX, USA, 12-14 August 2013.

29. Villars, P.; Calvert, L.D. Pearson's Handbook of Crystallographic Data for Intermetallic Phases; ASM International: Novelty, OH, USA, 1991; ISBN 978-0-87170-416-0.

30. Bandyopadhyay, J.; Gupta, K.P. Low temperature lattice parameters of Al and Al-Zn alloys and Grüneisen parameter of Al. Cryogenics 1978, 18, 54-55. [CrossRef]

31. DIN EN ISO 25178-2:2012-09 Geometrical Product Specifications (GPS)-Surface Texture: Areal-Part 2: Terms, Definitions and Surface Texture Parameters (ISO 25178-2:2012), German version EN ISO 25178-2:2012; Beuth Verlag: Berlin, Germany, 2012. [CrossRef]

32. Schwaighofer, E.; Clemens, H.; Mayer, S.; Lindemann, J.; Klose, J.; Smarsly, W.; Güther, V. Microstructural design and mechanical properties of a cast and heat-treated intermetallic multi-phase $\gamma$-TiAl based alloy. Intermetallics 2014, 44, 128-140. [CrossRef]

33. Kan, W.; Chen, B.; Peng, H.; Liang, Y.; Lin, J. Formation of columnar lamellar colony grain structure in a high Nb-TiAl alloy by electron beam melting. J. Alloys Compd. 2019, 809, 151673. [CrossRef]

34. Körner, C.; Bauereiß, A.; Attar, E. Fundamental consolidation mechanisms during selective beam melting of powders. Model. Simul. Mater. Sci. Eng. 2013, 21, 085011. [CrossRef]

35. Lou, S.; Jiang, X.; Sun, W.; Zeng, W.; Pagani, L.; Scott, P.J. Characterisation methods for powder bed fusion processed surface topography. Precis. Eng. 2019, 57, 1-15. [CrossRef]

36. Klassen, A.; Forster, V.E.; Juechter, V.; Körner, C. Numerical simulation of multi-component evaporation during selective electron beam melting of TiAl. J. Mater. Process. Technol. 2017, 247, 280-288. [CrossRef]

37. Juechter, V. Grundlagen des Selektiven Elektronenstrahlschmelzens von Titanaluminiden. Ph.D. Thesis, Friedrich-AlexanderUniversität Erlangen-Nürnberg, Erlangen, Germany, 2018.

38. Barriobero-Vila, P.; Gussone, J.; Stark, A.; Schell, N.; Haubrich, J.; Requena, G. Peritectic titanium alloys for 3D printing. Nat. Commun. 2018, 9, 3426. [CrossRef] [PubMed] 